\title{
COMBINED USE OF ACTIVE AND PASSIVE SURFACE WAVES FOR SHALLOW SUBSURFACE INVESTIGATION IN NOISY URBAN AREA OF SÃO PAULO CITY, BRAZIL
}

\author{
Claus Naves Eikmeier ${ }^{1}$, Renato Luiz Prado ${ }^{2}$ and Fabio Taioli ${ }^{3}$
}

\begin{abstract}
The dynamic shear modulus $\left(G_{\text {din }}\right)$ is important for geotechnical engineering, particularly for calculating the dynamic response of foundations. $G_{\text {din }}$ is determined from material densities and S-wave propagation velocity $\left(V_{S}\right)$. Usually, crosshole test is used for such determination. However, it is an expensive and invasive technique because it is based on drilling. The MASW method (Multichannel Analysis of Surface Waves) becomes an interesting option for being faster, more economical and easier to carry out. This paper presents results obtained with MASW method in a densely built up area with high traffic noise level in São Paulo city, Brazil. Results are compared with those obtained by crosshole test as well as geotechnical sounding data. The influence of some acquisition parameters was evaluated in data quality and final inversion result. Besides, it was also tested the passive mode test that is recording ambient noise. Best results were obtained by joint inversion of fundamental and higher curve modes extracted from stacked images generated from data acquired employing sledgehammer and passive sources. Final $V_{S}$ models were coherent with results obtained from crosshole seismic testing and mechanical sounding description, demonstrating MASW method can generate important information for geological and geotechnical investigation of urban areas.
\end{abstract}

Keywords: MASW, seismic, Rayleigh wave, velocity profile, dispersion curve.

RESUMO. 0 módulo de cisalhamento dinâmico $\left(\mathrm{G}_{\text {din }}\right)$ é importante para a engenharia geotécnica, particularmente nos cálculos de fundações sujeitas a esforços dinâmicos. $0 \mathrm{G}_{\text {din }}$ é determinado a partir das densidades dos materiais e das velocidades de propagação das ondas $S\left(V_{S}\right)$. Normalmente se utiliza o ensaio crosshole, ensaio sísmico entre poços, para tal determinação, porém, trata-se de uma aquisição de execução dispendiosa. Este trabalho apresenta resultados obtidos com o método MASW em umaárea densamente edificada e com alto nível de ruído de tráfego na cidade de São Paulo, Brasil, que são comparados com os obtidos por ensaio crosshole, assim como com dados de sondagem direta. Avaliou-se, também, a influência de alguns parâmetros de aquisição na qualidade do dado e no resultado final da inversão. Testou-se ainda a aquisição de dados no modo passivo, ou seja, registrando-se o ruído ambiental. Os melhores resultados foram obtidos utilizando-se inversão conjunta dos modos fundamental e superiores das curvas extraídas do empilhamento das imagens de dispersão dos dados gerados com as fontes marreta e passiva. Os modelos de $V_{S}$ obtidos foram coerentes com os resultados obtidos do ensaio sísmico crosshole e da descrição da sondagem mecânica, demonstrando que o método MASW pode gerar importantes informações para investigações geológicas e geotécnicas de áreas urbanas.

Palavras-chave: MASW, sísmica, onda Rayleigh, perfil de velocidades, curva de dispersão.

\footnotetext{
1 Universidade de São Paulo (USP), Institute of Astronomy, Geophysics and Atmospheric Sciences (IAG), Rua do Matão, 1226, Butantã, 05508-090 São Paulo, SP, Brazil. Phone: +55(11) 98593-3314 - E-mail: eikmeier.cn@gmail.com

2 Universidade de São Paulo (USP), Institute of Astronomy, Geophysics and Atmospheric Sciences (IAG), Department of Geophysics, Rua do Matão, 1226, Butantã, 05508-090 São Paulo, SP, Brazil. Phone: +55(11) 3091-5034; Fax: +55(11) 3091-5034 - E-mail: renato.prado@iag.usp.br

3 Universidade de São Paulo (USP), Institute of Geosciences (IGc), Department of Sedimentary and Environmental Geology, Rua do Matão, 1226, Butantã, 05508-090 São Paulo, SP, Brazil. Phone: +55(11) 3091-4200; Fax: +55(11)3091-4207 - E-mail: ftaioli@usp.br
} 


\section{INTRODUCTION}

Obtaining dynamic shear modulus $\left(G_{\text {din }}\right)$ is important for several geotechnical engineering designs, such as for calculating the dynamic response of foundations. $G_{\text {din }}$ is obtained from material densities and $\mathrm{S}$-waves propagation velocities $\left(\mathrm{V}_{\mathrm{S}}\right)$. Crosshole seismic (ASTM, 2007) test stands out from seismic methods employed to determine $V_{S}$ in situ as can sample expressive massif volumes and is considered the most accurate for geotechnical engineering. However, it has disadvantages because execution with casing and grouting of, at least, two boreholes are necessary, turning it into time-consuming and costly.

Thus, Multichannel Analysis of Surface Waves method, more commonly known by its acronym MASW, introduced by Park et al. (1999a), became a very interesting option for S-wave velocity mapping of shallow subsurface $(<50 \mathrm{~m})$. That method allows estimating $1 \mathrm{D}$ seismic velocity models by the inversion of surface wave dispersion curves. Two-dimensional (2D) sections can be generated from interpolation between several $1 \mathrm{D}$ profile results of and assist in the mapping of geological and geotechnical strata. Specific surface wave characteristics, such as the ease for their generation and record, enable MASW application in areas where other geophysical methods prove to be inadequate because of high environment noise level as in urban areas. On the other hand, due to inherent ambiguity of inversion processes, 1D velocity model generated from dispersion curve has higher degree of uncertainty in comparison with velocity models obtained by other seismic methods (for example, seismic refraction). Consequently, MASW method is more appropriate for geological and geotechnical recognition investigations of areas, or in feasibility stage of engineering projects, once the degree of accuracy is compatible with usually assumed simplifications in these situations.

This paper presents results obtained with MASW method in a densely built-up area with high traffic noise in São Paulo city, Brazil. Near the study area a few years earlier MASW data were acquired, crosshole seismic test and mechanical sounding (percussion and rotary) were accomplished to get information about $V_{S}$ values and geological and geotechnical parameters to subsidize São Paulo Metro line construction project.

Using exclusively unidirectional arrangement, MASW test was programmed to obtain a $1 D V_{S}$ profile. The influence of some acquisition parameters was also evaluated in data quality and final inversion result, testing different active seismic sources (sledgehammer and weight drop), different minimum offsets (source geophone array distance), and geophone spacing. A posteriori, due to the significant and permanent record of surface waves generated in the area by intense vehicle traffic (it means, pas- sive surface wave source), it was opted to analyze these data, in spite of the restrictive aspect of unidirectional array use in surveys recording passive data because of possible multiplicity of wave source positions.

Data obtained from MASW method were correlated with crosshole seismic test ( $V_{S}$ profile) aiming at evaluating MASW potentials and limitations for geotechnical investigation in urban areas. Final velocity models were also correlated with SPT (Standard Penetration Test) information as well as with subsurface material information extracted from mechanical sounding profile.

\section{STUDY AREA LOCATION AND GEOLOGICAL ASPECTS}

The study area is located in São Paulo city, Brazil, approximately $10 \mathrm{~km}$ from the downtown in SW direction. Figure 1 shows the area image indicating locations where crosshole seismic and MASW tests were performed as well as mechanical sounding.

In the study area, rock mass consists of gneissic rocks from Granitic-Magmatic Ibiúna Complex (Hasui et al., 1993), covered by residual soils and colluvial deposits. In some places, Tertiary sediments of São Paulo Sedimentary Basin and recent alluvial deposits overlie weathered rocks or bedrocks. The rock mass records the occurrence of two major ductile deformation processes (Hasui, 1993). The first involved a thrust tectonics that imposed generalized modifications to rocks with the development of several foliation types. The second process resulted in the development of large ductile transcurrent areas represented by Caucaia Shear Zone. It has relatively homogeneous distinct portions with three basic rock types: granitic mylonitic gneiss massif, biotitic mylonitic gneiss massif, and banded mylonitic gneiss massif (IPT, 1998).

Particularly in the study area, a mechanical sounding (percussion and rotary) was conducted with Standard Penetration Test (SPT). Lithological profile and SPT data are shown in Figure 2. Basically lithology consists of colluvium/residual soil, saprolite, weathered gneiss and sound gneiss. The material between $7.5 \mathrm{~m}$ and $11 \mathrm{~m}$ deep, representative of the transitional zone between colluvium and residual soil were not recovered. SPT value, number of blows (NSPT), suffers slight increment in colluvial to residual soil transition (5 $\mathrm{m}$ to $11 \mathrm{~m}$ ), and large increment in residual soil to saprolite transition (17 $\mathrm{m}$ to $35 \mathrm{~m}$ ). Between depths of $20 \mathrm{~m}$ and $23 \mathrm{~m}$ as well as between $26 \mathrm{~m}$ and $35 \mathrm{~m}$ there is sound rock, being interpreted as probable boulders. The presence of these unaltered rock and saprolite intercalations with respective seismic wave propagation velocity inversion evidently becomes an additional complicating factor in velocity profile determination as in crosshole as in MASW methods. 


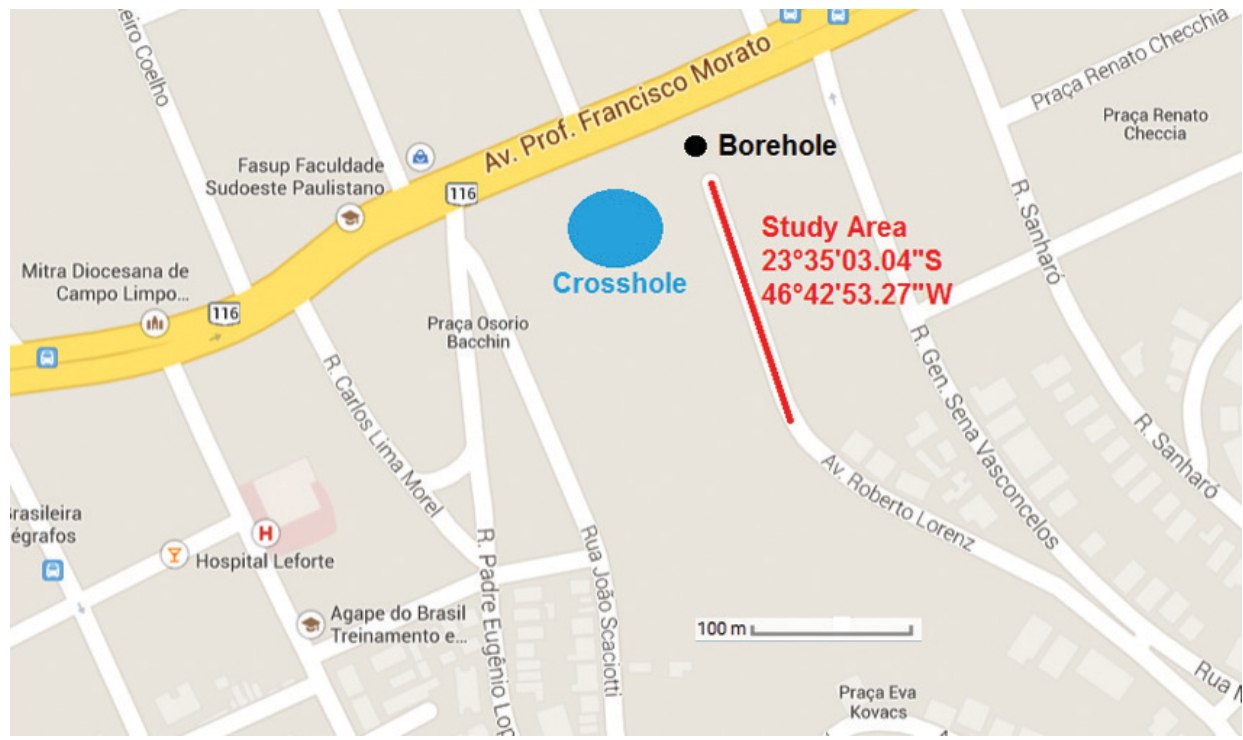

Figure 1 - Study area with the seismic line location in red; crosshole test in blue, and mechanical sounding in black (Google Earth, 2013).

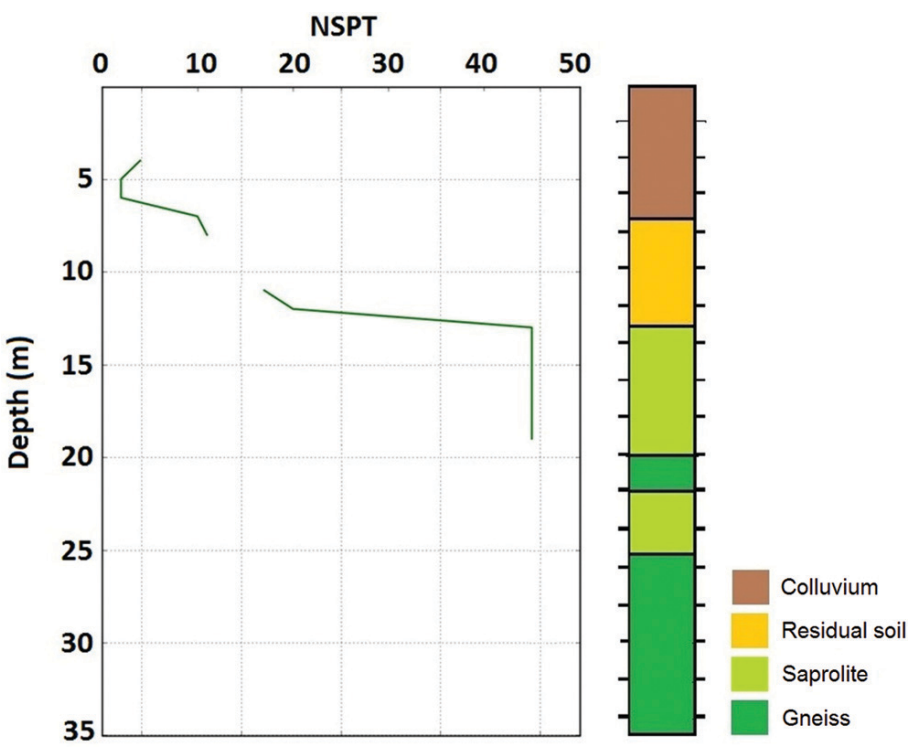

Figure 2 - Geological sounding profile and NSPT values.

\section{METHODOLOGY}

MASW method is based on dispersive Rayleigh wave behavior in propagating on a vertically heterogeneous medium. Different wavelengths reach different depths, eventually involving different geological layers. Elastic properties of involved layer determine phase velocities of different wavelengths. The aim of that method is to obtain a shear wave velocity profile by depth, once Rayleigh wave propagation velocity $\left(V_{R}\right)$ essentially depends on S-wave propagation velocity $\left(V_{R} \approx 0.9 V_{S}\right)$.
In stratified media, Rayleigh wave propagation has multimodal behavior. Under a physical point of view, constructive interference between waves and their reflections in interfaces amid layers explains the existence of different propagation modes for a determined frequency (Lai \& Rix, 1998; Strobbia, 2003). Except for the first mode (fundamental), there are higher modes only from a particular frequency called cutoff frequency. The diverse modes may or may not be identifiable, depending on the energy associated with each one. The use of higher modes in inversion process is interesting because it can generate deeper velocity models. 
A major advantage of using Rayleigh waves is due to its remarkable and distinguished record in seismograms, whether generated by active or passive sources. Rayleigh waves carry 2/3 of total energy generated by surface sources (Richard et al., 1970), and its attenuation due to geometrical spreading is lower than body waves.

Acquisition step is similar to that one used in refraction or reflection seismic testing, it means, a source generates seismic waves captured by geophones linearly arranged, recording a seismogram. In processing step, dispersion curve showing the relation between phase velocity and wave frequency is extracted. Obtained dispersion curve usually involves transformation of seismogram of offset-time domain to frequency-wavenumber domain. Through inversion process of the dispersion curves, Swave velocity profile by depth (Park et al., 1999b) is obtained.

For acquisitions employing active sources (sledgehammer and weight drop), linear arrangements are used with geophone interval and minimum and maximum offset adopted according to specific research criteria, for instance, desired vertical resolution for shallower strata and maximum research depth, aimed at higher signal-to-noise ratio (considering signal here as surface wave record; and coherent noise as body wave records). Foti et al. (2014) present extensive discussion regarding fundaments and criteria for choosing the best acquisition parameters for MASW using active and/or passive sources. Usually, in shallow investigation, it is adopted an acquisition time window $(\mathrm{T})$, large enough to record the whole surface wave field, with the suggested minimum value given by

$$
T=L / V_{\min }
$$

ratio, where $L$ refers to geophone array length, and $V_{\min }$ to minimum expected wave velocity. With vertical impact sources, it is used vertical component geophones, whose natural frequency depends on desired research scale. The lowest registered frequency $\left(f_{\min }\right)$ determines the highest expected-investigation depth $\left(Z_{\max }\right)$, according to

$$
Z_{\max }=V f_{\min } /\left(2 f_{\min }\right)
$$

relation, where $\mathrm{Vf}_{\min }$ is minimum frequency wave phase velocity (Rix \& Leipski, 1991). For shallow tests in geotechnical engineering scale, geophones with natural frequencies between $4.5 \mathrm{~Hz}$ and $14 \mathrm{~Hz}$ are preferred.

The lower generated frequency in investigated area depends basically on the source of seismic waves and the medium response. Usually, lighter sources, such as a sledgehammer impact, generate waves in a higher frequency-spectrum range, and release less energy than heavier weight drop sources. In tests with active sources, signal-to-noise ratio $(\mathrm{S} / \mathrm{N})$ can be increased by record vertical stacking. Normally, due to the elastic surface-material properties, lighter sources, such as sledgehammer, restrict the research to shallower horizons (up to $15 \mathrm{~m}$, for example). On the other hand, heavier sources, such as weight drop, present higher difficulty in field operation, and significantly spend more acquisition time. Choices of geometric parameters as distance between geophones, minimum and maximum offsets are conditioned by minimum and maximum wavelength to be sampled implying in the minimum and maximum desired investigation depth (empirical rule considers $Z \approx 0.5 \lambda$ ), and by $S / N$ ratio.

Using traffic noise as wave source, unidirectional arrangements should be avoided due to the usual source position randomness that can also result in different spectral content. In this case, bidirectional arrangements should preferably be used (more practical to be employed in urban areas) or in circle also implying in the use of processing techniques that consider the wave parameter analysis in two dimensions. However, linear arrangement for passive measures has an advantage when simultaneous data acquisition with active source is considered. Nevertheless, in the case of wave field generated by passive source does not represent a uniform, isotropic field as well as in the existence of multiple wave generator points, linear arrangement is going to record field projection in only one direction, which may generate fake results (Foti et al., 2014).

Obtaining dispersion image from field seismogram, usually applies double Fourier transform (2D FFT) in order to data are analyzed and processed in frequency-wavenumber ( $f-k$ ) domain. Then, an energy density image by frequency and wavenumber is obtained. From

$$
V=2 \pi f / \kappa
$$

equation the transformation to phase velocity-frequency $(\mathrm{v}, \mathrm{f})$ domain is done. The software Surfseis (KGS, 2006), employed in this research, uses the phase-shift method (Park et al., 1999a) for the wave field transformation. The method is based on the estimation of the phase differences of different traces (firstly transform a shot gather into the frequency-domain and then calculate phasevelocity applying an offset-dependent phase shift).

Subsequently, the dispersion curve from observed maximum energies is extracted. When dispersion curve is obtained, a $1 \mathrm{D}$ layered model based on shear wave velocity $\left(V_{S}\right)$ is inferred through inversion process. Rayleigh wave phase velocity is a function of earth parameters, of S- and P-wave velocities, layers densities and thicknesses. However, S-wave velocities mainly control variations in Rayleigh wave velocities (Xia et al., 1999). 
Crosshole seismic method consists in body wave generation in a hole and its record in one or more collinear adjacent holes; source and geophones must be at the same elevation level to each record. The aim is to record the wave directly transmitted between source and receivers in order to obtain wave velocity values ( $P$ and/or $S$ ) to each elevation level. For this reason, spacing between holes should be short to avoid the record of refracted waves as first arrivals (ASTM, 2007).

SPT aims at determining the resistance penetration rate (NSPT) of soil and geological materials (ABNT/NBR 6484). NSPT represents the impact number of a $65 \mathrm{~kg}$ weight in free fall from a height of $75 \mathrm{~cm}$, necessary for a sample tube to penetrate $30 \mathrm{~cm}$ (considered the last two $15 \mathrm{~cm}$ segments of a total penetration interval of $45 \mathrm{~cm}$ ). If NSPT exceeds 50 stroke values and the penetration is less than $45 \mathrm{~cm}$, consider the index NSPT/ (penetration interval in cm). NSPT values allow good soil shear strength estimate, that's why there are several empirical correlations of them with $V_{S}$ values (Hasancebi \& Ulusay, 2007; Dikmen, 2009).

\section{DATA ACQUISITION AND PROCESSING}

In acquisition, linear arrangement of geophones and source was adopted; source was externally positioned to geophones array (inline offset). A 48 channel acquisition system (Geode model, of Geometrics Inc.) was used with $4.5 \mathrm{~Hz}$ geophones. As active wave sources, sledgehammer (approximately $6 \mathrm{~kg}$ ) impact on a metal plate and weight drop of $30 \mathrm{~kg}$ (height of $1.7 \mathrm{~m}$ with minimal air resistance) were used. Vertical stacking number was varied only during the use of sledgehammer source. Wave records generated by vehicle traffic (passive source) on Francisco Morato Avenue, perpendicularly placed to arrangement line in an approximate distance of 40 meters (Fig. 1) were also done.

Although linear array use to passive measures presents advantages under operational point of view, it can cause problems if recorded wave field does not represent a uniform, isotropic field, as this arrangement type will record wave field projection in one direction. However, in study area, the traffic noise source of higher energy was mostly aligned with the geophone array. Thus, it is assumed that the angle between array direction and source azimuth was close to zero, which suggest that the wavelengths records were close to real values.

Table 1 shows different acquisition parameters adopted during tests.

Tests with two active sources (sledgehammer and weight drop) aim at evaluating the increase in investigation depth that potentially could be obtained with the use of more powerful sources under test conditions.
Crosshole data were obtained from 3 boreholes perpendicularly aligned to Francisco Morato avenue direction. An end hole was used for wave source positioning, the others, distant $3 \mathrm{~m}$ and $5 \mathrm{~m}$ from source hole, were employed to geophones setting. Tests were performed every meter from surface to $23 \mathrm{~m}$ depth, always with source and geophones positioned at the same elevation. Records of first tested levels (up to $5 \mathrm{~m}$ deep) were not analyzed because traffic noise level in the avenue did not allow identification of S-wave arrival. $V_{S}$ values were calculated considering S-wave travel time differences between geophones in order to eliminate any eventual imprecision of equipment trigger. Borehole deviation measurements were not obtained, and then the same distance between boreholes measured on the ground surface was considered for all tested levels.

MASW data processing was performed with the Surfseis software (KGS, 2006), following the flow chart: i) acquisition geometry edition; ii) mute of refraction and air waves of records obtained with active sources; iii) f-k filtering of records obtained with active sources to attenuate the surface waves generated by Francisco Morato avenue traffic.

The dispersion analysis starts with obtaining the dispersion image (also called velocity spectrum) and extracting the dispersion curve(s).

Two algorithms available in Surfseis were employed for the curve inversion process. Based on gradient method (Xia et al., 1999), the first one performs the experimental dispersion curve inversion extracted from dispersion image through iterative process. In this case, only the dispersion curve inversion of fundamental mode is done. The initial model is defined from information of experimental dispersion curve (maximum depth based on longer wavelength of the extracted curve, model of 10 increasingthickness layers, Poisson's ratio and densities equal to 0.4 and $2 \mathrm{~g} / \mathrm{cm}^{3}$, respectively) or other a priori defined model. At the Surfseis, the iterations of the inversion process finish when either the minimum RMSE or the maximum number of iterations is reached. Both values can be setted in the begining of the inversion process. The fit between the theoretical and the experimental curves of the fundamental mode was evaluated, in this work, on the root-mean-square error (RMSE). The formula employed to calculate the minimum RMSE (which give weight to dispersion data based on signal-to-noise ratio) at the ith iteration in Surfseis is:

$$
R M S E=\sqrt{\frac{\sum_{k=1}^{M}\left[O^{k}-T_{k}^{i}\right]^{2}}{\operatorname{tr}(w)}}
$$

where $O$ and $T$ are the observed and calculated phase velocities, $w^{k}$ is the weight of the $k$ th data and $\operatorname{tr}(w)$ is the sum of the weights $\left(\sum_{k=1}^{M} w^{k}\right)$. 
Table 1 - Acquisition parameters used in the tests.

\begin{tabular}{|c|c|c|c|c|c|}
\hline Source & $\begin{array}{c}\text { Minimum } \\
\text { Offset } \\
(\mathrm{m})\end{array}$ & $\begin{array}{c}\text { Maximum } \\
\text { Offset } \\
(\mathrm{m})\end{array}$ & $\begin{array}{c}\text { Geoph. } \\
\text { interval } \\
(\mathrm{m})\end{array}$ & $\begin{array}{c}\text { Time } \\
\text { window } \\
(\mathrm{s})\end{array}$ & $\begin{array}{c}\text { Vertical } \\
\text { stacking }\end{array}$ \\
\hline $\begin{array}{c}\text { Sledgehammer } \\
\text { Weight drop }\end{array}$ & 5 or 10 & $52-57$ & 1 & 2 & 1 to 6 \\
Passive & $5,15,20$ and 30 & $52-124$ & 1 or 2 & 2 & 1 \\
\hline
\end{tabular}

The second algorithm uses Monte Carlo method that, considering a layer model, randomly search curves that best adjust to dispersion image. In this case, it is also possible to perform a multimodal curves inversion taking into account the fundamental and the higher mode curves.

This inversion process begins with forward modeling (Schwab \& Knopoff, 1972) of dispersion curves from a geological model of up to 5 layers (the last representing half-space) characterized by the parameters thickness, $V_{S}, V_{P}$, Poisson's ratio, and density. Search process is automatic and iterative, with initial model update and random search process in every step.

The second process was specially used for dispersion image interpretation where energies associated with higher modes were recognized. To evaluate the matching degree between modeled curves and the background dispersion image for each curve, it is considered the energy associated to each one (the energy of a dispersion-curve point is normalized along the phase-velocity axis). The relative weighting of each mode is specified in terms of percentage.

\section{RESULTS}

Results presented herein are records obtained with sledgehammer and weight drop sources as well as cultural noise (vehicular traffic, mainly). Various analyzes were performed to comparatively evaluate the quality of data obtained with active sources, varying the minimum offset and/or geophones spacing. For the studied area, significant differences were not observed with changing these parameters, and for that reason specific results are not shown. However, in a general way, $5 \mathrm{~m}$ minimum offsets and $1 \mathrm{~m}$ geophone spacing resulted in better dispersion images of sledgehammer data. Regarding weight drop source, data obtained with $15 \mathrm{~m}$ minimum offsets and $2 \mathrm{~m}$ geophone spacing generated better dispersion images. Regarding cultural noise records, the best images were obtained when $2 \mathrm{~m}$ geophone spacing and 60 s time window were used.

Initial comparative analysis of amplitude spectra of records obtained from different sources (sledgehammer, weight drop, and traffic noise) indicated that, in relation to the active sources, while the released energy by weight drop source is higher than the sledgehammer one, the dominant frequency band was not significantly different as it could be expected (Fig. 3b). Regarding to spectrum obtained with passive source records, the energy is higher than those obtained with the other two sources, and dominant frequency band is shifted to lower frequencies (Fig. 3a) indicating, in this case, the possibility of mapping layers at greater depths.

Combined effects of energy released by source, natural geophone frequency and medium response - that can be in part analyzed from Figure 3 amplitude spectra - also determine the quality and characteristics of dispersion images obtained from seismograms. Figure 4 shows some selected dispersion images from different sources and arrangements.

Increase in information regarding lower frequencies in image generated from passive source record (Fig. 4c) is clearly observed, while images generated from sledgehammer and weight drop sources are similar (Figs. 4a and 4b) and quite noisy in the lowest frequency band. However, in active source images, higher modes can be identified; the same does not happen in the passive source image. Figure $4 \mathrm{~d}$ also presents the graph with all dispersion curves extracted from Figures 4a, 4b, 4c. Comparative curve analysis shows that data generated by passive and weight drop sources (arrangements with $2 \mathrm{~m}$ geophones interval) result in images that allow the extraction of dispersion curves comprising lower frequencies.

Nevertheless, inversions of fundamental mode dispersion curve obtained from sledgehammer and drop weight source records, shown in Figure 4, resulted in similar velocity models (Fig. 5), limited to approximately 8 meter maximum depth. Velocity values are very close to those ones obtained with crosshole seismic testing; the approximately 6 meter interface observed in velocity model can be correlated to NSPT value increase (Fig. 2) observed in the same depth.

Due to the complementarity between dispersion images generated from passive and active source records, i.e., lower frequency bandwidth sampling in passive case, and higher mode 
a)

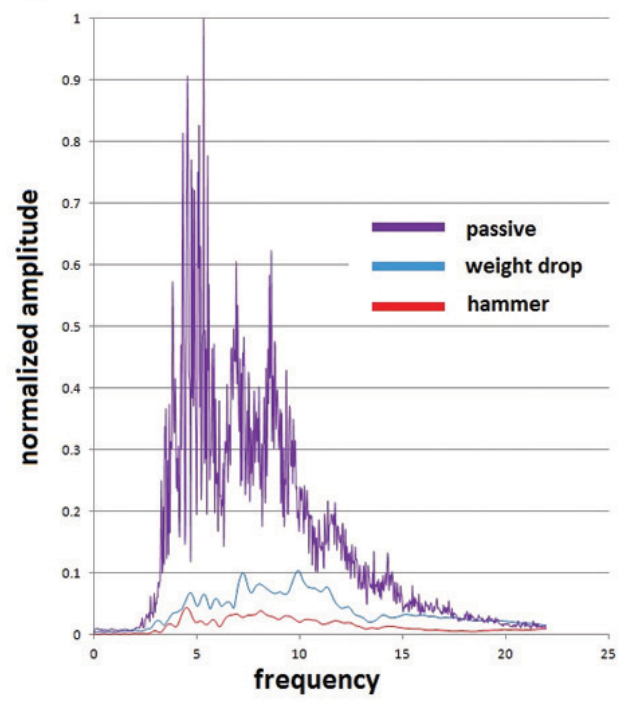

b)

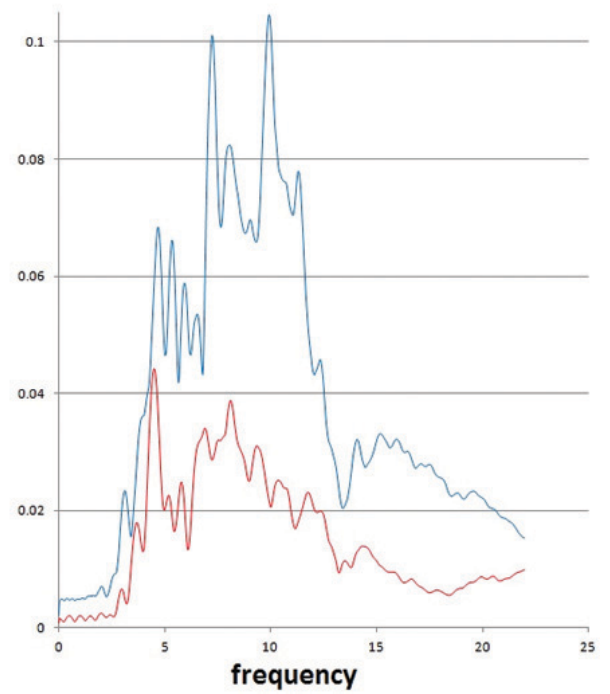

Figure 3 - Normalized amplitude spectra of records obtained with sledgehammer, weight drop, and passive sources (a); zooming of the spectra of sledgehammer and weight drop data (b).

a)

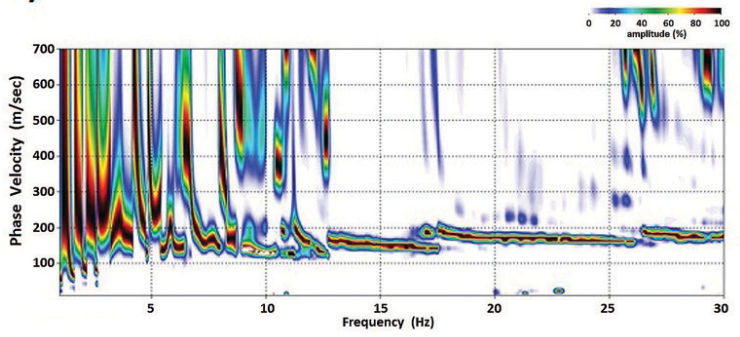

c)

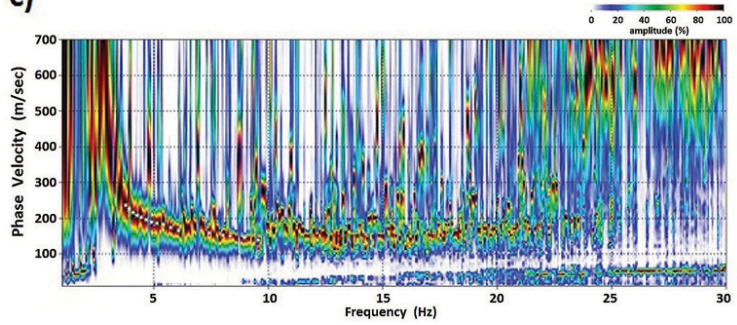

b)

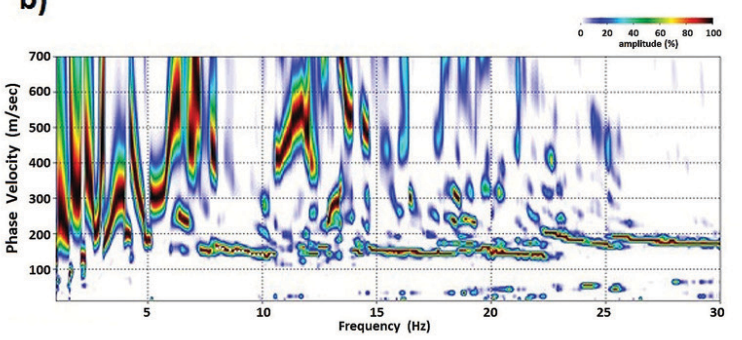

d)

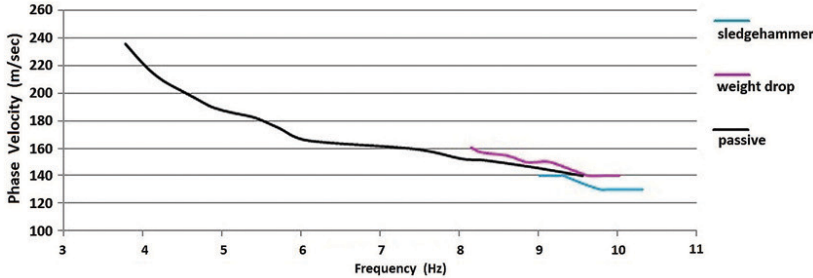

Figure 4 -Recorded dispersion images obtained (a) with sledgehammer source, minimum offset of $5 \mathrm{~m}$, and geophone interval of $1 \mathrm{~m}$; (b) weight drop source, minimum offset of $15 \mathrm{~m}$, and geophone interval of $2 \mathrm{~m}$; (c) passive source, geophone interval of $2 \mathrm{~m}$, and (d) dispersion curves (fundamental mode) extracted from images.

sampling in active case, stacking of both images was carried on, as suggested in Park et al. (2005). Whereas, in this experiment, images generated from sledgehammer and drop weight source records were similar, it was decided by sledgehammer record, once as methodological proposal the joint use of passive and sledgehammer sources is more interesting due to operational difficulties for weight drop source use. The energy associated with higher modes tends to be more dominant with large offset use. Moreover, considering the same wavelength, higher modes bring deeper information than the fundamental one (Xia et al., 2000). Stacked image result is presented in Figure 6.

Results of fundamental mode curve inversions from recorded images obtained only with passive data (Fig. 4c), and stacking image (Fig. 6) are shown in Figure 7. It is observed the same trend for velocity distribution with depth but with differences in the positioning of the lithology interfaces. In inversion process by gradient method, it is worth to point out that the algorithm considers a model with continuous velocity increase with depth. In comparing 


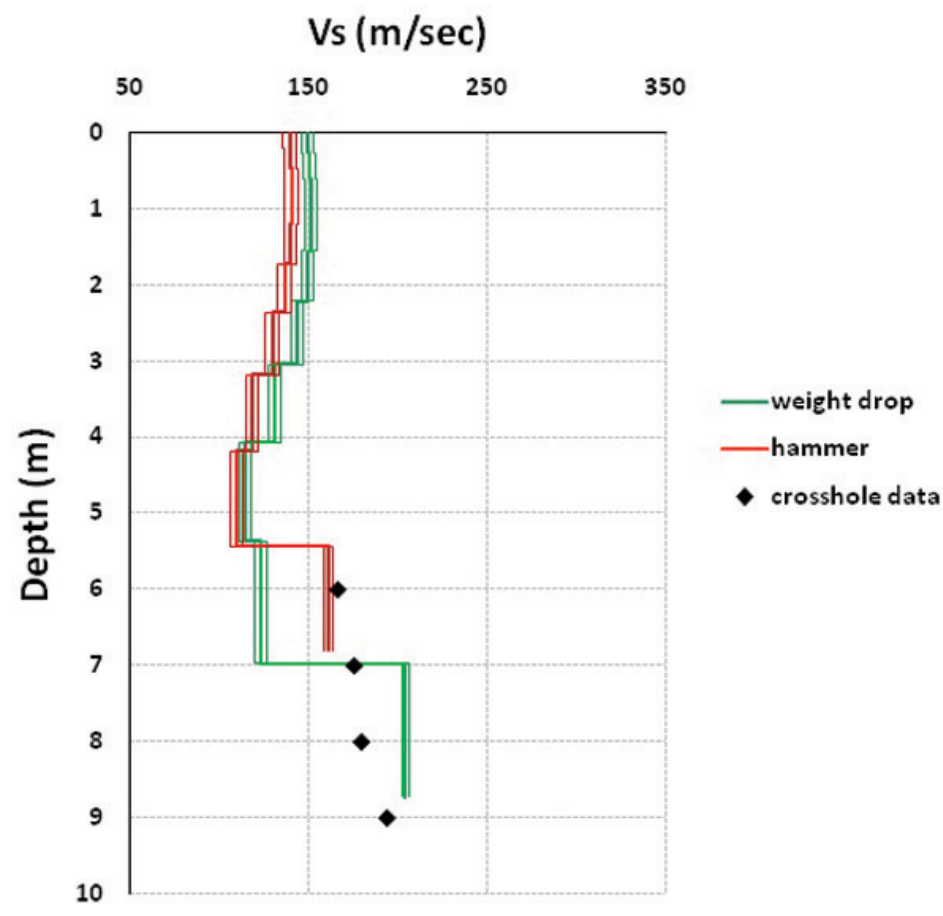

Figure $\mathbf{5}$ - S-wave velocity model with depth obtained from crosshole test (only up to $9 \mathrm{~m}$ of depth), and dispersion curve inversions of fundamental mode extracted from recorded images obtained with sledgehammer (with maximum RMS errors of $3.6 \mathrm{~m} / \mathrm{s}$ ) and weight drop sources (with maximum RMS errors of $3.3 \mathrm{~m} / \mathrm{s}$ ).

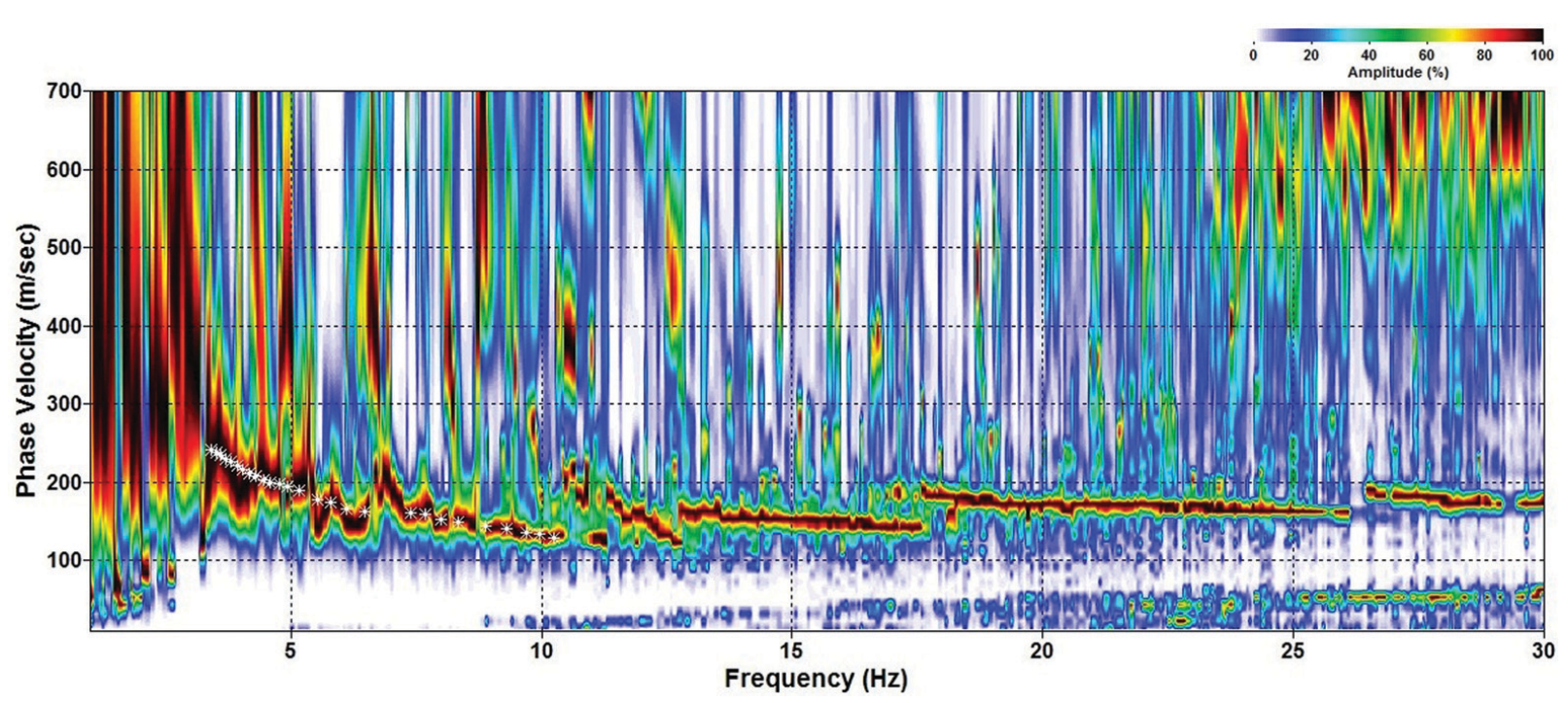

Figure 6 - Dispersion image stacking from dispersion image obtained with sledgehammer (Fig. 4a) and passive (Fig. 4c) sources with extracted fundamental mode curve indication.

with $V_{S}$ values obtained with crosshole seismic test, it is observed these are a little lower from $10 \mathrm{~m}$ of depth; the apparent interface to approximately $11 \mathrm{~m}$ of depth, interpreted from crosshole data, is absent in the resulting inversion model.

Aiming at increasing the investigation depth, the joint inver- sion of fundamental and higher mode curve was done. Dispersion images were analyzed resultant from data image stacking obtained by sledgehammer and passive sources (Fig. 8b), and data obtained with sledgehammer (Fig. 8a), in this case considering only the higher modes. 


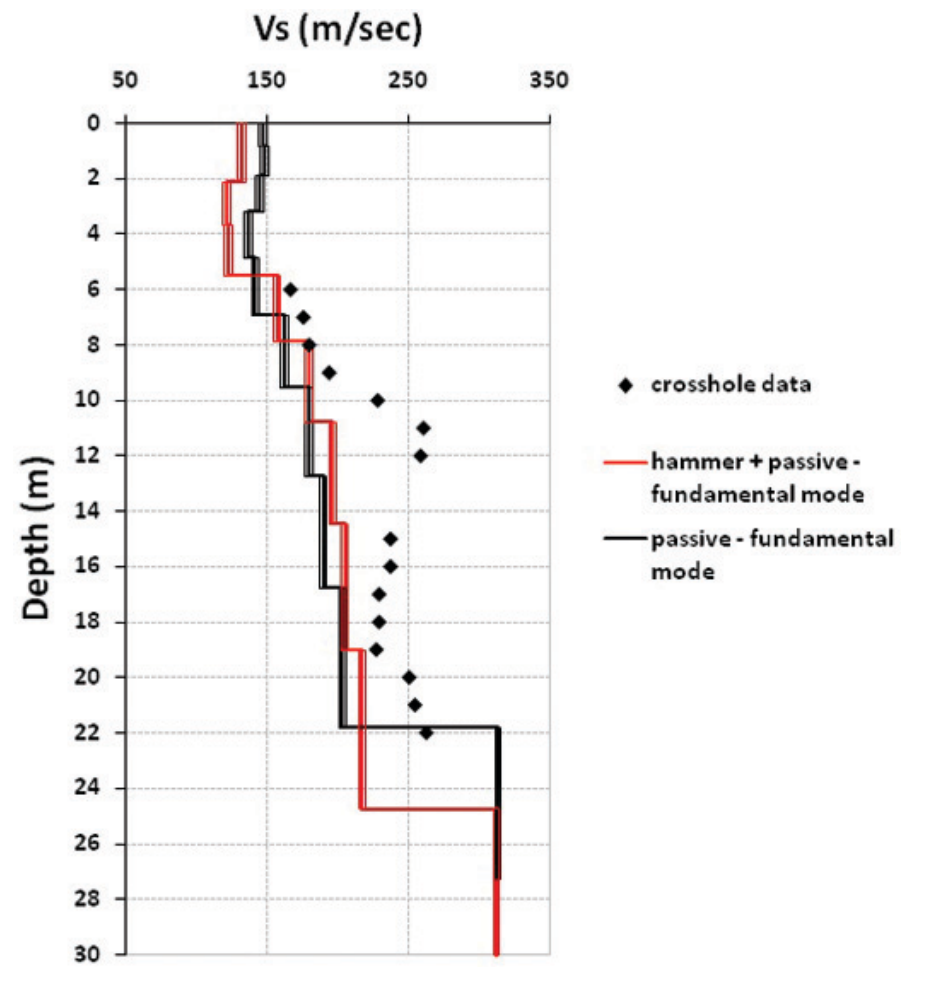

Figure 7 - S-wave velocity models with depth obtained from crosshole test and dispersion curve inversions of fundamental mode extracted from dispersion images of sledgehammer and passive data (with maximum RMS error of $2.9 \mathrm{~m} / \mathrm{s}$ ).
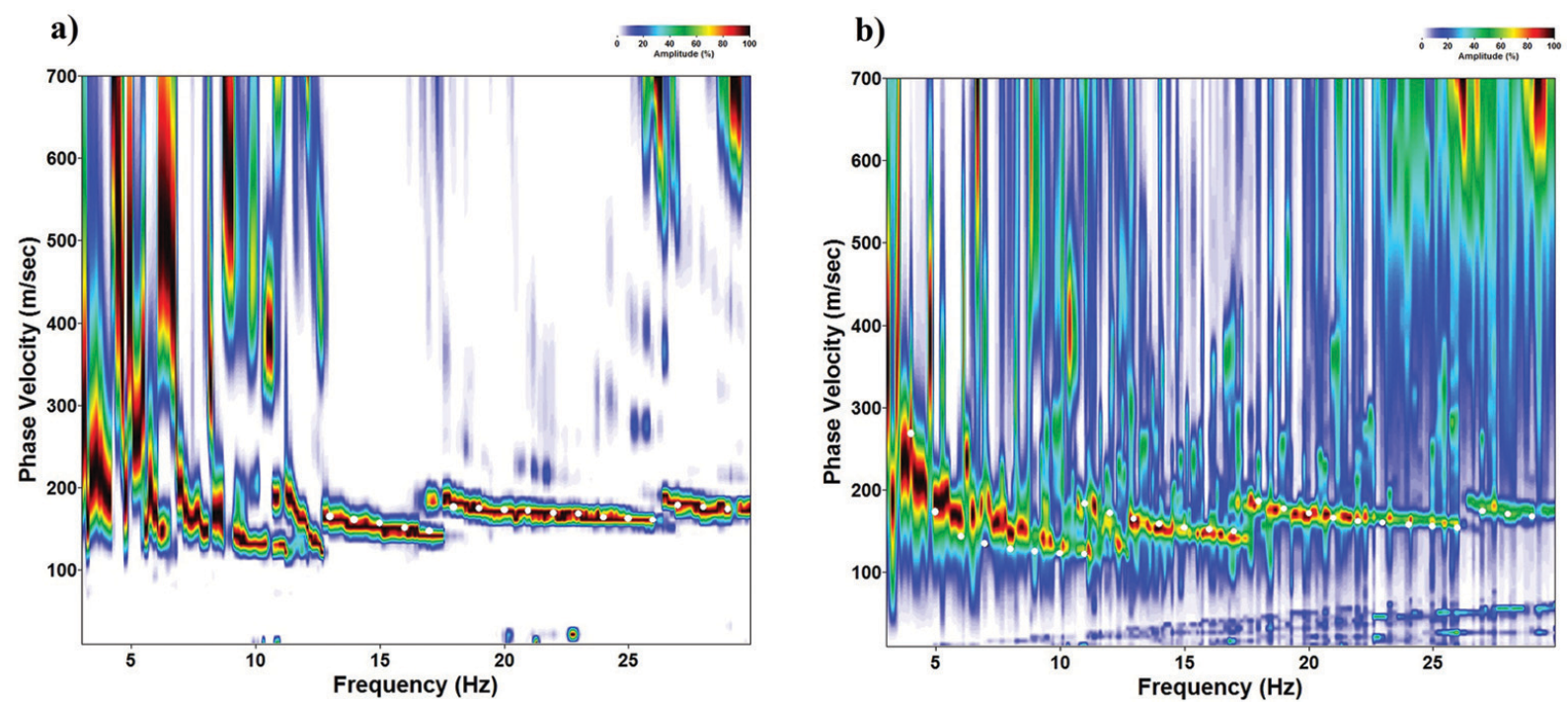

Figure 8 - Dispersion images indicating higher mode curves extracted from (a) sledgehammer data, and (b) sledgehammer + passive combination (fundamental + higher modes).

Results are shown in Figure 9 graph. In this inversion process with Monte Carlo method algorithm, interfaces of initial model were established from the sounding profile information, especially
NSPT data, and from lithological classification (Fig. 2). The final model, considering results of two inversions (Fig. 9), indicates interfaces to approximately $5 \mathrm{~m}, 12 \mathrm{~m}$ and $21 \mathrm{~m}$ in depth and 


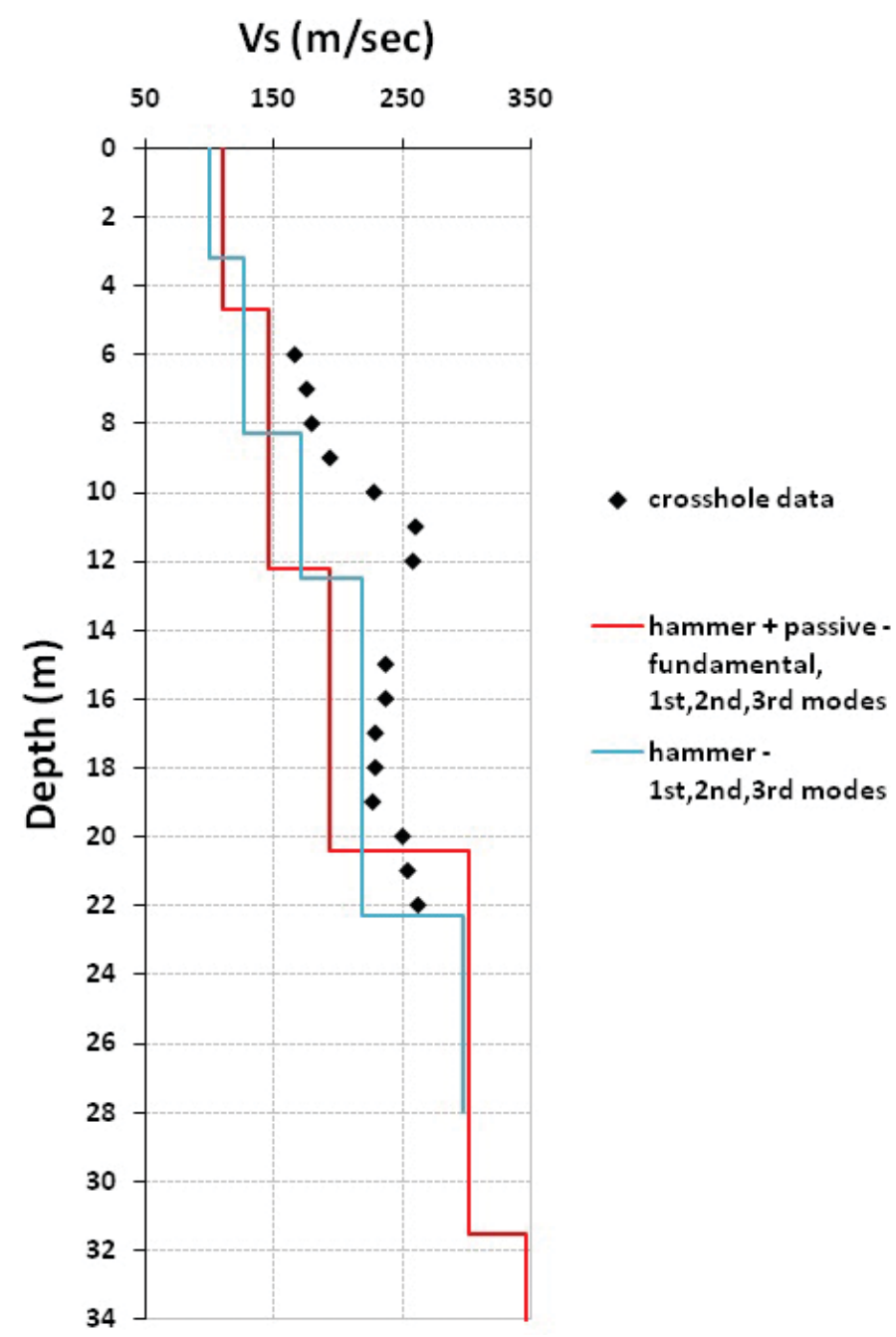

Figure $\mathbf{9}$ - S-wave velocity models with depth obtained from multimodal curve inversions of sledgehammer and passive data (with fitting degree of $31 \%$ for fundamental mode, $63 \%$ for 1 st higher mode and $64 \%$ for the 2nd higher mode), and sledgehammer data (with fitting degree of $38 \%$ for 1 st higher mode, $21 \%$ for the 2 nd higher mode and $6 \%$ for the 3 rd higher mode).

generally lower velocities but close of those obtained with crosshole seismic testing.

Finally, Figure 10 shows NSPT, crosshole seismic and MASW data (Fig. 9) as well as sounding lithological interpretation. It is observed the result of joint inversion of fundamental (extracted from passive source data), and higher (extracted from sledgehammer source data) mode dispersion curves presents four major interfaces: i) approximately $5 \mathrm{~m}$ depth where NSPT value increase and close to residual soil contact is observed; ii) approximately $12 \mathrm{~m}$ where there also are NSPT value increase, significant $\mathrm{V}_{\mathrm{S}}$ values increase obtained with crosshole testing, and where there is residual soil contact with saprolite; iii) approximately $21 \mathrm{~m}$ where an increase of $V_{S}$ values of crosshole data and saprolite-gneiss contact are observed.

It is important to point out that crosshole test, mechanical sounding and MASW study areas are different, although they are very close (Fig. 1). Furthermore, dispersion curve inversion result is associated with average wave propagation behavior along the entire geophone array, and the other data reflect a punctual geology information. This may explain the existence of the interface to approximately $32 \mathrm{~m}$ depth of model obtained with MASW test, and not observed in mechanical sounding profile. $V_{S}$ values obtained from dispersion curve inversion were consistently lower than those ones obtained with crosshole testing. It should be 


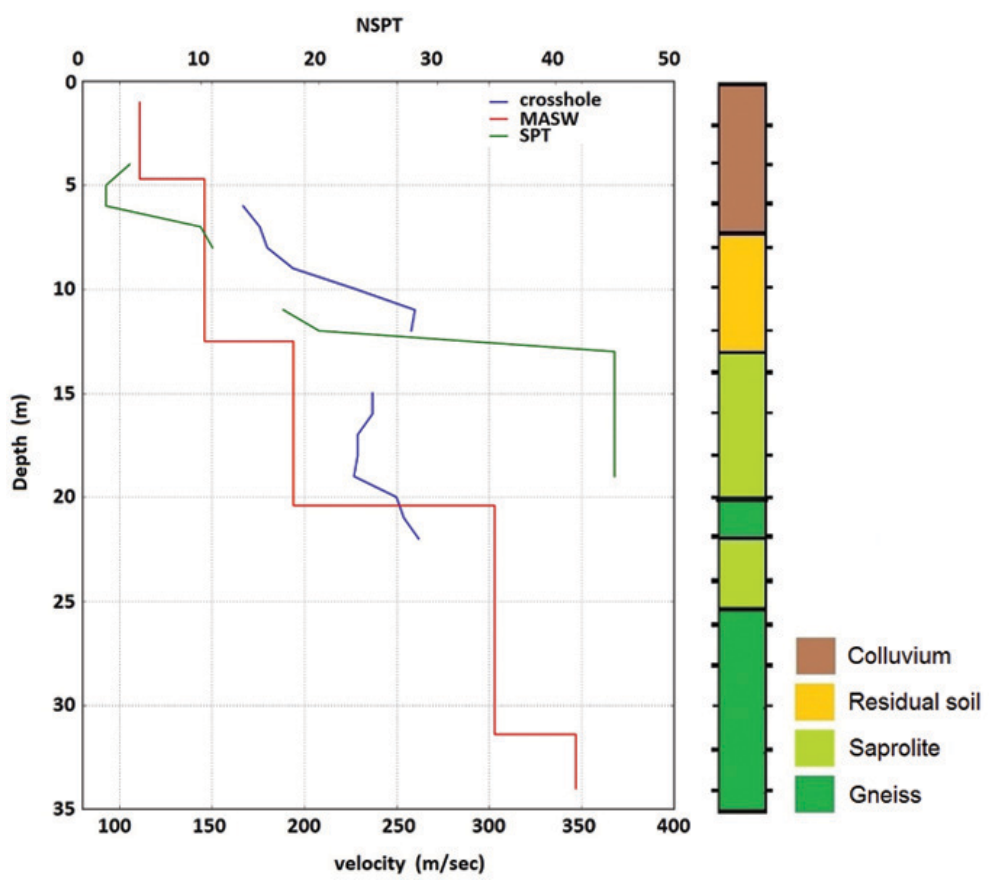

Figure 10 - Comparison among NSPT, crosshole and MASW data as well as lithological description.

observed in crosshole test case, $V_{S}$ values were obtained by dividing the measured surface distance between borehole receivers by the arrival time at each respective seismogram. It is expected, in media with steady velocity increase with depth, the minimumtime ray trajectories are curved resulting in $V_{S}$ values systematically higher than the real ones.

\section{CONCLUSIONS}

This paper presented results obtained with MASW method in a densely built up area with high traffic noise level in São Paulo city, Brazil. Results were compared with those obtained by crosshole test as well as geotechnical sounding data. In addition the use of two different active seismic sources, different minimum offsets, different geophones spacings and passive source were studied. The results analysis showed that MASW- $V_{S}$ models were coherent with crosshole seismic testing data and also the mechanical sounding description. The major $V_{S}$ changes in the model were coincident with the lithology and physical properties changes. The comparison of the different seismic sources showed no significant advantages in active weight drop source use in relation to sledgehammer in terms of inversion results. Therefore, considering operational aspects, the use of sledgehammer proved to be more advantageous. Variations of minimum offsets and geophones spacing under accomplished test conditions did not result also in differences in the quality of obtained dispersion images. The use of passive source (vehicle traffic noise) was important, even adopting linear arrangement, once under test conditions the main traffic noise source was in general aligned with the geophone array. Dispersion curves from passive source records sampled lower frequency, consequently allowed greater depth models. The joint inversion of the fundamental and higher modes of curves (extracted from dispersion image stacking of data obtained with sledgehammer and passive sources) led to a consistent with the reality and greater-depth geological model. The final model showed that the MASW method is a good tool for mapping the weathering profile and basement. It has great applications potential for underground urban works and geologicalgeotechnical characterization in phases of engineering-project feasibility and preconstruction.

\section{ACKNOWLEDGEMENTS}

This work was supported by the Conselho Nacional de Desenvolvimento Científico e Tecnológico (CNPq), the Institute of Astronomy, Geophysics and Atmospheric Sciences (IAG) and the Institute of Geosciences (IGC), both from Universidade de São Paulo (USP). We thank the geologist Marcelo D. Monteiro (Metrô - São Paulo subway company) for providing the geotechnical sounding logs and the anonymous reviewers whose comments and suggestions contributed to improve this manuscript. 


\section{REFERENCES}

ABNT - Associação Brasileira de Normas Técnicas. 2001. Execução de sondagens de simples reconhecimento dos solos - NBR-6484.

ASTM - American Society for Testing and Materials. 2007. Standard test methods for Crosshole Seismic Testing. ASTM standard, D4428/D4428M-07. ASTM.

DIKMEN U. 2009. Statistical correlations of shear wave velocity and penetration resistance for soils. Journal of Geophysics and Engineering, 6: $61-72$.

FOTI S, LAI CG, RIX GJ \& STROBBIA C. 2014. Surface Wave Methods for Near-Surface Site Characterization. CRC Press, 487 pp.

HASANCEBI N \& ULUSAY R. 2007. Empirical correlations between shear wave velocity and penetration resistance for ground shaking assessments. Bulletin of Engineering Geology and the Environment, 66: 203213.

HASUI Y, HARALYI NLE \& COSTA JBS. 1993. A megaestruturação do Pré-Cambriano brasileiro com base em dados geofísicos e geológicos. Geociências (UNESP), 12(1): 7-31.

IPT - Instituto de Pesquisas Tecnológicas do Estado de São Paulo. 1998. Caracterização geomecânica do maciço rochoso do trecho Faria Lima Vila Sônia, Linha 4 - Amarela. São Paulo, Relatório IPT 36891. 146 pp.

KGS - Kansas Geological Survey. 2006. SurfSeis [computer software], ver. 2.0.

LAI CG \& RIX GJ. 1998. Simultaneous inversion of Rayleigh phase velocity and attenuation for near-surface site characterization. PhD Dissertation, Georgia Institute of Technology, USA, 258 pp.
PARK CB, MILLERRD \& XIA JH. 1999a. Multichannel analysis of surface waves. Geophysics, 64(3): 800-808.

PARK CB, MILLER RD, XIA JH, HUNTER JA \& HARRIS JB. 1999b. Higher mode observation by the MASW method. Expanded Abstracts, Society of Exploration Geophysicists, p. 524-527.

PARK CB, MILLER RD, RYDEN N, XIA JH \& IVANOV J. 2005. Combined use of active and passive surface waves. Journal of Environmental Engineering Geophysics, 10: 323-334.

RICHART FE Jr, HALL JR Jr \& WOODS RD. 1970. Vibrations of Soils and Foundations. Prentice-Hall, Englewood Cliffs, 414 pp.

RIX GJ \& LEIPSKI EA. 1991. Accuracy and resolution of surface wave inversion. In: BHATIA SK \& BLANEY GW (Eds.). Recent advances in instrumentation, data acquisition and testing in soil dynamics. American Society of Civil Engineers, p. 17-32.

SCHWAB F \& KNOPOFF L. 1970. Surface wave dispersion computations. Bull. Seism. Soc. Am., 60: 321-344.

STROBBIA C. 2003. Surface Wave Method. Acquisition, Processing and Inversion. PhD Thesis, Politecnico di Torino, Torino, Italy, 317 pp.

XIA J, MILLER RD \& PARK CB. 1999. Estimation of near-surface shearwave velocity by inversion of Rayleigh waves. Geophysics, 64(3): 691700.

XIA J, MILLER RD, PARK CB, HUNTER JA \& HARRIS JB. 2000. Comparing shear-wave velocity profiles from MASW with borehole measurements in unconsolidated sediments, Fraser River Delta, B.C., Canada. Journal of Environmental Engineering Geophysics, 5(3): 1-13. 